\title{
Ecofisiologia de plantas forrageiras
}

\section{Róberson Machado Pimentel ${ }^{1 *}$, Geraldo Fábio Viana Bayão ${ }^{1}$, Daiana Lopes Lelis ${ }^{2}$, Alex Júnio da Silva Cardoso ${ }^{2}$, Felipe Vélez Saldarriaga ${ }^{2}$, Carlos Cicinato Vieira Melo ${ }^{3}$, Filipe Bittencourt Machado de Souza ${ }^{3}$, Ana Claúdia de Souza Pimentel ${ }^{4}$, Dilermando Miranda da Fonseca ${ }^{5}$, Manoel Eduardo Rozalino Santos ${ }^{6}$}

\author{
${ }^{1}$ Doutor em Zootecnia - Universidade Federal de Viçosa (UFV), Viçosa, Minas Gerais, Brasil \\ ${ }^{2}$ Alunos de Mestrado - Universidade Federal de Viçosa (UFV), Viçosa, Minas Gerais Brasil \\ ${ }^{3}$ Doutor em Zootecnia - Universidade Federal de Lavras (UFL), Lavras, Minas Gerais, Brasil \\ ${ }^{4}$ Aluno de Graduação - Universidade Federal de Viçosa (UFV), Viçosa, Minas Gerais, Brasil \\ ${ }^{5}$ Professsor Doutor - Departamento de Zootecnia, Universidade Federal de Viçosa (UFV), Viçosa, Minas Gerais, Brasil \\ ${ }^{6}$ Professsor Doutor - Departamento de Zootecnia, Universidade Federal de Uberlândia (UFU), Uberlândia, Minas Gerais, \\ Brasil \\ *Autor para correspondência E-mail: rmpzoo@yahoo.com.br
}

RESUMO. O trabalho foi desenvolvido com o objetivo de realizar uma revisão acerca da importância da ecofisiologia das plantas forrageiras, ao abordar os impactos dos fatores bióticos e abióticos sobre as plantas e suas respostas morfofisiológicas. O estresse físico ocasionado pela compactação do solo prejudica o desenvolvimento do sistema radicular, sendo apresentada como resposta da planta maior emissão de raízes laterais como alternativa para explorar maior volume de solo. A condição de alagamento prejudica as espécies forrageiras de maneira diferenciada. Nesse ambiente, as plantas mais adaptadas apresentam a formação de raízes adventícias. Na condição de seca as plantas tolerantes possuem a capacidade de aprofundar o sistema radicular, além de possuírem modificações anatômicas e fisiológicas para sobreviverem. $\mathrm{O}$ pastejo diminui o aparato fotossintético das plantas e para recuperarem da desfolhação e manterem produtivas ocorrem alterações na população de perfilhos e na relação entre fonte e dreno dos órgãos remanescentes. No ambiente de sombra o maior limitante é a baixa radiação solar. As forrageiras sob a influência da sombra priorizam a partição de fotoassimilados para a parte aérea em detrimento das raízes e, também, possuem adaptações anatômicas e fisiológicas na lâmina foliar para interceptar e absorver maior quantidade de luz. A deficiência de nutrientes prejudica o crescimento da comunidade de plantas, como alternativa as mesmas estimulam o desenvolvimento do sistema radicular com o objetivo de suprir a demanda por esse recurso. As adaptações da planta aos fatores bióticos e abióticos promovem alterações nas suas características para garantir a sobrevivência, mas que não necessariamente implicam em manutenção da produção dos órgãos de interesse. Contudo, tais modificações devem ser conhecidas para respeitar os limites de utilização e garantir a eficiência de produção das forrageiras.

Palavras chave: Estresse da planta, fatores bióticos e abióticos, respostas morfofisiológicas

\section{Ecophysiology of forage plants}

ABSTRACT. The study was conducted in order to conduct a review of the importance of ecophysiology of forage plants, to address the impacts of biotic and abiotic factors on plants and their morphological and physiological responses. The physical stress caused by soil compaction affect the development of the root system, is this condition plant shown as response greater emission lateral roots as an alternative to explore larger volume of soil. The flooding condition affect forage species differently. In this environment, the most adapted plants present the formation of adventitious roots. In dry condition tolerant plants have the ability to deepen the root system, besides their anatomical and physiological modifications to survive. Grazing reduces the photosynthetic apparatus of 
plants and to recover from defoliation and maintain productive changes occur in the population of tillers and the relationship between source and sink of the remaining organs. In the shadow environment the most limitation is the low solar radiation. Forage under the influence of shadow prioritize assimilates partition to shoot at the expense of roots and also have anatomical and physiological adaptations in the leaf blade to intercept and absorb more light. The nutrient deficiency impairs the growth of the plant community, as an alternative the same stimulate the development of the root system in order to meet the demand for this resource. The plant adaptation to biotic and abiotic factors promote changes in its characteristics to ensure survival, but that does not necessarily imply maintaining production of the organs of interest. However, such changes must be known to respect the limits of use and ensure of forage production efficiency.

Keywords: Biotic and abiotic factors, morphological and physiological responses, plant stress

\section{Introdução}

A ecofisiologia é um ramo da ciência que estuda as respostas morfofisiológicas das plantas nos ambientes. $\mathrm{O}$ entendimento dessas alterações permite ao homem estabelecer práticas de manejo consistentes com a capacidade produtiva das plantas forrageiras em cada situação em particular. Antes de compreender a importância da ecofisiologia para as plantas forrageiras, os trabalhos e ações de manejos realizados possuíam um enfoque simplista e pragmático do processo produtivo baseado em pastagens (Silva \& Nascimento Jr., 2007). O conhecimento obtido apresentava pouco alcance, pois invariavelmente, as eventuais mudanças no ambiente ou microclima impediam a extrapolação dos resultados de pesquisa.

$\mathrm{O}$ estudo da ecofisiologia procura entender a interação de plantas individuais dentro de sua comunidade e de suas consequências sobre a dinâmica estrutural do relvado (Silva et al., 2008), assim como, os mecanismos adaptativos da planta ao estresse imposto pelos fatores bióticos e abióticos do ecossistema da pastagem (Lemaire, 2001).

Nesse sentido, o estresse pode ser caracterizado como uma condição adversa, na qual inibi o funcionamento normal e o bem estar de sistemas biológicos (Mahajan \& Tuteja, 2005). De acordo com esses autores, as plantas ao sofrerem estresse recebem uma série de sinais em suas células receptoras, que desencadeiam respostas na tentativa de se manterem produtivas e perenes no ecossistema. A magnitude dessas alterações depende da capacidade de adaptação da planta a essa nova condição (Bengough et al., 2006).
O objetivo desta revisão foi abordar os impactos dos fatores bióticos e abióticos sobre as plantas e suas respostas morfofisiológicas em cada condição de estresse.

\section{Compactação do solo}

O termo compactação pode ser descrito como decréscimo de volume do solo quando uma determinada pressão externa é aplicada sobre o mesmo. Os fatores responsáveis por essas alterações no solo podem ser de natureza externa ou interna. Intrinsecamente a textura e estrutura do solo determinam o arranjo das partículas do solo e definem a densidade inicial do solo, enquanto as pressões exercidas no meio externo podem ser decorrentes de atividades agropecuárias (Richart et al., 2005).

Não existe consenso na literatura sobre o nível crítico de densidade do solo, ou seja, o valor acima do qual o solo é considerado compactado. Apesar disso, é comum relacionar o crescimento radicular em solos compactados com sua densidade, mas é necessário compreender que para cada solo existe uma densidade considerada crítica ao crescimento da raiz. Reichert et al. (2003) propuseram densidades do solo críticas para algumas classes de textura, sendo 1,30 a $1,40 \mathrm{Mg} \mathrm{m}^{-3}$ para solos argilosos, de 1,40 a 1,50 $\mathrm{Mg} \mathrm{m}^{-3}$ para os franco-argilosos e de 1,70 a 1,80 $\mathrm{Mg} \mathrm{m}{ }^{-3}$ para os franco-arenosos. Mas alguns autores afirmam que para solos argilosos e arenosos densidades superiores a 1,45 e $1,70 \mathrm{Mg}$ $\mathrm{m}^{-3}$, respectivamente, superam os níveis críticos (Torres \& Saraiva, 1999). Nesse mesmo sentido, Reichert et al. (2009) propuseram equações para estimar a densidade crítica do solo, e encontram, uma alta correlação negativa entre o conteúdo de 
argila e os valores de densidades que limitam a produtividade das culturas.

O estresse físico ocasionado pela alta resistência do solo a penetração das raízes pode limitar a aquisição de recursos essenciais, como água e nutrientes às plantas. De acordo com Bengough et al. (2006), solos compactados podem inibir o alongamento celular e prejudicar o crescimento radicular. Esses autores relatam que o pico de tensão ocorre no ápice da coifa da raiz e, por isso, algumas plantas apresentam crescimento compensatório emitindo maior proporção de raízes laterais. Reinert et al. (2008) ao avaliarem o perfil radicular de plantas de cobertura em argilossolo vermelho, constataram que em valores de densidade do solo entre 1,75 e $1,85 \mathrm{Mg} \mathrm{m}^{-3}$, o sistema radicular teve engrossamento, desvios e ramificações de grau moderado, mas o crescimento em profundidade foi pouco afetado. Para densidades superiores a $1,85 \mathrm{Mg} \mathrm{m}^{-3}$, considerado crítico para o crescimento das plantas, o sistema radicular teve dificuldade de crescer, com modificações na morfologia das raízes, como grande engrossamento, desvios em ângulos de até $90^{\circ} \mathrm{e}$, em casos mais severos, a raiz teve seu crescimento inibido a maiores profundidades. A emissão de raízes laterais em porções menos compactada do solo parece ser uma alternativa da planta para explorar maior volume de solo. No entanto, essa estratégia pode restringir o sistema radicular a camadas superficiais, tornando a forrageira susceptível a possíveis danos ocasionados pelo déficit hídrico.

No ambiente pastoril os aumentos em densidade do solo são ocasionados pela combinação entre o excesso de animais em pastejo e baixa massa residual do pasto, que amplifica as forças de pressões dos cascos dos animais. Em área de várzea Vizzotto et al. (2000) constatou que após 116 dias de pastejo o pisoteio animal reduziu a porosidade total e aumentou a densidade do solo na camada superficial. Estudos realizados em solos compactados na Nova Zelândia, por Harrison et al. (1994), demonstraram que a utilização do subsolador diminuiu a densidade do solo em $11 \%$ e aumentou a porosidade do solo. Em resposta ao ambiente mais favorável ao sistema radicular, as forrageiras apresentaram maior comprimento e melhor distribuição vertical das raízes no perfil do solo que resultaram em maior produtividade dos pastos.
Em outro estudo, Cabral et al. (2012) observaram diminuição na concentração dos teores de nitrogênio, fósforo e potássio nas folhas de $B$. brizantha e $P$. maximum à medida que a compactação do solo aumentava, pois absorção dos nutrientes foi limitada pelo baixo crescimento radicular. Stirzaker et al. (1996) ao trabalhar com plantas de cevada (Hordeum vulgare cv. Yagan) em solos com densidades crescentes de 1,12 a $1,78 \mathrm{Mg} \mathrm{m}^{-3}$, em ambiente controlado, observaram que as maiores densidades ocasionaram redução na área foliar, no comprimento radicular e biomassa de raiz. Nesse estudo a compactação do solo diminui em $15,32 \%$ a biomassa da parte aérea e em 27,50\% a biomassa de raiz, o que resultou em aumento da razão parte aérea/raiz. Em virtude dessas alterações, o sistema radicular ficou limitado a explorar pequeno volume de solo restringindo o fornecimento de água e nutrientes para a planta. Em experimento de campo com a mesma espécie, Arvidsson (1999) ratifica essa informação ao avaliar a concentração dos nutrientes na planta submetidas a crescentes pressões sobre o terreno. As plantas de cevada sob condições extremas de compactação tiveram menor produção e concentração de nutrientes, especialmente, fósforo e potássio que são íons transportados por mecanismo de difusão, e, portanto, necessitam de maior proximidade entre a raiz e o nutriente para que ocorra a absorção. Além disso, as informações geradas nesse estudo concluem que a compactação gerou decréscimo na porosidade total e diminuição da aeração, que resultaram em perdas de nitrogênio por denitrificação e menor mineralização do carbono.

\section{Alagamento}

Nas pastagens tropicais o excesso de água no solo pode ser ocasionado pela combinação entre intensos períodos de precipitação e compactação do solo que impedem a drenagem da chuva. Durante esse período, o excesso de água pode causar danos irreversíveis na comunidade de plantas, inclusive comprometendo sua sobrevivência. Estresse dessa natureza está sujeito a ocorrem com maior frequência em todo o mundo, por causa das mudanças climáticas induzidas por atividades antropogênicas que tendem a concentrar as precipitações em períodos mais restritos do ano (IPCC, 2007).

Em trabalho de revisão, Colmer \& Voesenec (2009) descrevem os efeitos fisiológicos que podem acometer as plantas estressadas por 
alagamento. Dentre as principais alterações, ocorre a baixa disponibilidade de ATP a nível celular podendo levar a deterioração de componentes celulares pela ruptura da integridade das membranas. A reduzida formação de ATP inicia quando a célula inibe a fosforilação oxidativa pela falta do aceptor final de elétrons, o oxigênio. Em ambientes alagados a difusão do oxigênio é extremamente reduzida, assim limita a respiração mitocondrial nos órgãos submersos. Nessa condição, a célula produz energia via glicólise, porém essa rota metabólica é menos eficiente energeticamente e não atende a demanda da planta. Danos celulares também estão associados à formação de espécies reativas de oxigênio como os radicais superóxido, radicais hidroxila, hidrogênio peróxido e oxigênio singleto. A deficiência de oxigênio em solos saturados pode ocasionar acúmulo de elétrons do Complexo III da mitocôndria e sobrecarregar a célula de poder redutor que leva a formação de espécies reativas de oxigênio. Outra consideração com relação aos baixos níveis de oxigênio em ambiente alagado é a redução de alguns componentes do solo para formar níveis tóxicos $\mathrm{Mn}^{2+}, \mathrm{Fe}^{2+}$ e $\mathrm{S}^{2-}$ que podem ser absorvidos e acumulados nos tecidos das raízes.

Para minimizar os efeitos deletérios do alagamento, as plantas mais adaptadas, recorrem a alterações de comportamento geneticamente definidos, mas estimulados pela condição adversa. Nesse sentido, Caetano et al. (2008) avaliaram a resposta de Brachiaria spp. submetida a curto período de alagamento. A interpretação dos resultados permite concluir que as forrageiras apresentam plasticidade fenotípica e fisiológica diferenciada que as permitem ser mais adaptadas ao excesso de água. Nessa pesquisa, as Brachiaria brizantha cultivares Marandu e Piatã tiveram as menores taxas de alongamento foliar, mas dentre as duas apenas a Marandu apresentou diferenças significativas com menores taxas de crescimento relativo da parte aérea e biomassa da raiz. Porém, as outras espécies avaliadas tiveram a taxa fotossintética comprometida pela baixa condutância estomática. Pesquisa conduzida por Dias-Filho (2002a) com espécies do mesmo gênero constataram diminuição no número de perfilhos, na taxa de alongamento foliar e na proporção de biomassa alocada para as raízes, ao passo que foram observados incrementos relativos na biomassa de colmo. Nessas plantas a fotossíntese foi drasticamente reduzida em função da baixa condutância estomática, ocasionado limitações na carboxilação pela restrição da entrada de $\mathrm{CO}_{2}$. Em outro estudo, Dias-Filho \& Carvalho (2000) avaliaram as alterações morfofisiológicas das $B$. brizantha, $B$. decumbens e $B$. humidicola submetidas a inundação. Nessa condição, $B$. brizantha mostrou ser a espécie menos tolerante, verificado pelas menores taxas de crescimento em relação ao seu controle. Esse menor crescimento foi decorrente dos maiores declínios na taxa de alongamento foliar, conteúdo total de clorofila e taxa fotossintética. As observações em ambos os trabalhos permitiram aos autores concluir que a taxa de alongamento foliar pode ser usado como parâmetro para detectar a tolerância das plantas ao alagamento, por ser uma característica de resposta imediata, além da vantagem de ser um método não destrutivo e não invasivo. Haddad et al. (2000) ao estudarem o comportamento de diferentes espécies forrageiras em diferentes períodos de alagamento concluíram que a $B$. mutica foi a mais tolerante, mesmo com o maior tempo de inundação, seguida pela $S$. anceps com tolerância intermediária e $B$. decumbens que foi a mais afetada ao apresentar menor produção de matéria seca de folhas e colmo e maior proporção de material morto, sendo consideradas não adaptadas as condições de alagamento.

Pesquisa conduzida por Mattos et al. (2005b), avaliaram a tolerância de espécies do gênero Brachiaria em dois níveis de estresse hídrico do solo, a partir da inundação de 1 e $10 \mathrm{~m}$ acima do solo. A partir de atributos morfogênicos foi possível constatar maiores taxas de senescência e menores de alongamento e área de lâminas nas maiores alturas de coluna de água. As alterações ocorridas na planta podem ser atribuídas ao efeito negativo que o alagamento teve sobre a fotossíntese líquida da folha. Dentre as espécies avaliadas apenas a B. mutica foi considerada tolerante ao excesso de água, visto que essa forrageira manteve a altas taxas fotossintéticas que não comprometeu sua produtividade, aliado ao aparecimento de numerosas raízes adventícias adaptadas para suprir o sistema radicular com oxigênio capturado do ar. Trabalho desenvolvido por Baruch (1994) testou a capacidade de adaptação das espécies Andropogon gayanus, Hyparrhenia rufa, Echinochloa polystachya e Bachiaria mutica em condições de alagamento. Em todos os tratamentos foi possível observar redução nas taxas de alongamento da folha e área foliar, principalmente para as espécies de 
Andropogon gayanus, Huparrhenia rufa, consideradas mais sensíveis ao ambiente sob hipóxia das raízes. Esse comportamento foi atribuído à redução na assimilação de carbono causado pela menor abertura estomacal, somado a deficiência de nitrogênio e potássio encontrado nas folhas. Essa menor absorção de nutrientes em raízes submersas foi em consequência de alterações no metabolismo da raiz, presença de níveis de tóxicos de outros elementos no ambiente reduzido e possíveis perdas por denitrificação que diminuem a disponibilidade de nitrogênio para as plantas. As espécies Echinochloa polystachya e Bachiaria mutica mostraram respostas adaptativas ao desenvolver grande quantidade de raízes adventícias e alongamento do colmo, além de possuírem características peculiares, como colmo oco e grande proporção de tecidos constituídos por aerênquimas, que auxiliam a oxigenação dos tecidos submersos.

Nesse contexto, alguns autores (Voesenek \& Pierik, 2008), sugerem a hipótese de que as plantas mais adaptadas ao ambiente alagado sofreram ao longo dos anos evolutivos, menor número de mutações, tendo em vista que as plantas terrestres foram originadas de suas predecessoras aquáticas.

De modo geral, as plantas que se desenvolvem em solos com excesso de água, mesmo as mais tolerantes, reduzem a partição de biomassa para as raízes. Essa estratégia diminui a respiração de mantença do sistema radicular, por que as raízes não são capazes de satisfazer seus próprios requerimentos de oxigênio, e, portanto, menor volume de raiz pode facilitar a oxigenação de seus tecidos pela parte aérea (Dias-Filho, 2002b).

\section{Seca}

O déficit hídrico é uma situação comum à produção de muitas culturas no mundo todo, fenômeno que está associado a fatores como ocorrência e distribuição das chuvas, demanda evaporativa e capacidade de armazenar água no solo. $\mathrm{Na}$ atualidade, a escassez de água é considerada a principal ameaça à segurança alimentar, por causa dos impactos negativos no crescimento e desenvolvimento das plantas (Farooq et al., 2009). A falta de água é um problema crônico da agricultura e a tendência é o seu agravamento com o avanço das áreas áridas em consequência do crescimento populacional e os efeitos antropogênicos (Chaves et al., 2003).
A baixa umidade do solo gera um conflito entre a conservação de água pela planta e a taxa de assimilação de $\mathrm{CO}_{2}$ para produção de carboidratos. Em períodos prolongados de deficiência hídrica mesmo as plantas mais adaptadas podem sofrer as consequências desse estresse.

Em estudo de revisão, Mahajan \& Tuteja (2005) relatam as principais alterações fisiológicos relacionados à falta de água nas plantas. A primeira resposta das plantas é diminuir a abertura do estômato para prevenir a perda de água por transpiração. $\mathrm{O}$ fechamento estomático pode se dar por mecanismo de acionamento hidropassivo ou metabólico. De modo passivo, as células guarda perdem água diretamente por evaporação, o que diminui turgescência celular e reflete em menor abertura dos poros do estômato. Metabolicamente esse processo é regulado pelo ABA (ácido abscísico), que promove o efluxo de íons de $\mathrm{K}^{+}$da célula guarda levando a perda de turgor nessas estruturas. A percepção de falta de água pode ser sinalizada inicialmente na raiz, sendo que essa sensibilidade de resposta é intermediada pelo $\mathrm{ABA}$ até as folhas que fecham seus estômatos. Em condição de seca severa não apenas o $\mathrm{CO}_{2}$ intracelular limita a fotossíntese, podem ocorrer também, danos celulares ao aparato fotossintético devido ao acúmulo de espécies de oxigênio reativo. Isso ocorre pelo declínio de $\mathrm{CO}_{2}$, que resulta numa acentuada redução dos componentes dentro da cadeia de transporte de elétrons que transferem os elétrons do Fotossistema I para o oxigênio gerando suas espécies reativas, deletérias as células.

A fim de superara os eventuais danos causados pela falta de água as plantas podem fazer ajuste de ordem morfologia, bioquímica e fisiológica para adaptar a essa condições. Foram constatados por Melo et al. (2007) que as espécies forrageiras apresentam plasticidade diferenciada para tolerar as condições de deficiência hídrica. Nesse experimento, foram observadas as mudanças ocasionadas em Setaria anceps e Paspalum paniculatum submetidos à suspensão total de água. Como adaptação morfologia as plantas de Setaria anceps apresentaram diminuição do diâmetro polar médio dos estômatos da porção adaxial, e em Paspalum paniculatum, houve aumento na densidade estomática e diminuição nos diâmetros polar e equatorial dos estômatos. Essas estratégias permitem as plantas maiores 
eficiência no uso da água, uma vez que estômatos menores com reduzida abertura de suas células apresentam maior efeito sobre o efluxo da água do que sobre o influxo de $\mathrm{CO}_{2}$, podendo assim, manter a assimilação de carbono para a fotossíntese e uma pequena perda de água por transpiração. Apesar das duas espécies serem adaptadas à seca, Paspalum paniculatum apresentou maior número de características favoráveis para superar a escassez de água. Essa planta se mostrou extremamente adaptada ao apresentar diminuição do diâmetro médio do metaxilema de suas raízes para reduzir a tensão hidráulica nos vasos do xilema, evitando a formação da cavitação. Além das alterações anatômicas, essa espécie acumulou aminoácidos e açúcares nas suas folhas para obter maior controle osmótico de suas células.

De fato, as plantas mais adaptadas lidam com a desidratação celular através de ajustamentos osmóticos exercidos pela acumulação de certos solutos. Nesse contexto, grande número de compostos sintetizados pelas plantas, tais como prolina, glutamato, carnitina, manitol, sorbitol e íons inorgânicos ajudam a evitar ou minimizar as perdas de água na célula (Mahajan \& Tuteja, 2005). Manter a célula hidratada significa conservar as atividades metabólicas do tecido e manter a integridade das estruturas celulares para permitir o crescimento das plantas (Chaves et al., 2003). Em estudo realizado por Singh et al. (2000), com trevo branco (Trifolium repens), foram observados relação positiva entre concentração de prolina e osmolaridade na seiva foliar e entre concentração de prolina e recuperação foliar após reidratação, o que demostra o papel do controle bioquímico das células vegetais na tolerância à seca.

A tolerância às condições de seca podem ser muito divergentes mesmo entre as espécies do mesmo gênero. Em estudo envolvendo a avaliação de quatro espécies do gênero Brachiaria, Guenni et al. (2004) constataram que Brachiaria humidicola e Brachiaria dictyoneura desenvolveram menos sinais de estresse em consequência da menor utilização de água no solo e manutenção de altas taxas fotossintéticas. A elevada fotossíntese nessas espécies não foi explicada apenas pela maior condutância estomática, nesse caso fatores como a manutenção da integridade do aparelho fotossintético podem ter contribuído. Santos et al. (2013) constataram aumento na proporção de material morto nas folhas de $B$. brizantha $\mathrm{cv}$.
Marandu, e consequente, diminuição na área foliar total como mecanismos utilizados para reduzir o consumo de água e equilibrar as suas relações hídricas em condições de estresse hídrico. Além do mais, essa espécie apresentou potencial osmótico menor que a $B$. brizantha $\mathrm{cv}$. BRS Piatã, ajuste necessário para absorver água de solos com baixa disponibilidade hídrica, uma vez que a Marandu extrai maiores quantidades de água para o crescimento. Mattos et al. (2005) verificaram maior tolerância a seca da $B$. brizantha $\mathrm{cv}$. Marandu dentre quatro espécies de Brachiaria avaliadas. Essa forrageira apresentou as maiores taxas de aparecimento e alongamento foliar, atribuída ao menor comprometimento das taxas fotossintéticas e sistema radicular profundo.

Modificações no sistema radicular também são esperados com a escassez de água no solo. Trabalhos conduzidos em condições controladas por Guenni et al. (2002) observaram que houve uma redistribuição do sistema radicular a maiores profundidades em plantas de espécies de Brachiaria submetidas à seca. Apesar do aprofundamento do sistema radicular, nesse estudo, todas as plantas apresentaram aumentos na razão parte aérea/raiz. Esse resultado a princípio contraditório, se deve ao crescimento compensatório das plantas sob estresse que receberam água por sete dias antes da colheita. A rápida retomada do alongamento foliar das plantas reidratadas superou inclusive os valores obtidos no tratamento controle sem restrição hídrica. Os autores explicam que os solutos acumulados na planta, não usados para biossíntese durante o período seco, permitiram um rápido incremento do crescimento foliar após a retomada as condições ideais de crescimento. Resultados contraditórios foram reportados por Baruch (1994), onde não foi constatado alteração na partição de foto assimilados entre raiz e parte aérea, que assim como no experimento anterior houve recuperação da planta do estresse hídrico antes de sua colheita para as avaliações. Com base nesses resultados, podemos concluir que os efeitos da escassez de água para as forrageiras nem sempre diminui a proporção da parte aérea em detrimento do sistema radicular. Essa resposta varia em função da plasticidade fenotípica da planta e da intensidade e duração da seca.

\section{Pastejo}

No manejo do pastejo é preciso administrar um conflito de interesses entre o animal e a planta. A forrageira precisa manter área foliar 
para continuar crescendo, ao passo que as folhas são utilizadas como alimento pelos animais. Portanto, para otimizar os sistemas de produção animal em pastagens é importante conhecer os aspectos morfofisiológicos das plantas forrageiras associadas ao efeito do pastejo na rebrota. O pastejo afeta as relações entre a comunidade vegetal, e também, entre os órgãos remanescentes da planta podendo influenciar na produtividade das gramíneas.

As plantas exibem diferentes estratégias de resistências aos danos causados pelos herbívoros, podendo evitar a desfolha via defesa ou escape no tempo e espaço, ou podem tolerar os danos. Ambas as estratégias representam uma alternativa evolutiva de resposta a herbívora e não são mutuamente exclusivas. Dentro desse contexto, as plantas forrageiras desenvolveram-se em habitat sujeito a pressões de pastejo e, portanto, a tolerância passa a ser uma resposta evolucionária mais estável para a comunidade vegetal e herbívora. Além disso, a tolerância está associada ao desenvolvimento de atributos diretamente relacionados ao crescimento, enquanto a defesa, por exemplo, envolve custos metabólicos direcionados a outras funções em vez do crescimento da planta (Rosenthal \& Kotanen, 1994).

Para as plantas adaptarem ao pastejo características fisiológicas e morfológicas podem ser alteradas. Nesse sentido, alguns trabalhos reportam a influencia do sistema radicular e colmo, como estratégia da planta a superar o estresse causado pelo pastejo. Trabalhos dessa natureza foram conduzidos por Gomide et al. (2002), onde observaram que a desfolha total do perfilho principal limitou a fotossíntese e comprometeu o crescimento do sistema radicular, mesmo com a utilização das reservas de carboidratos na base do colmo. No entanto, a manutenção de área foliar de aproximadamente $50 \%$ foi suficiente para não comprometer a formação da raiz. Resposta similar foi observada por Thornton \& Millard (1996), ao verificarem que o corte da parte aérea reduziu o crescimento de raízes, porém para compensar esse efeito as plantas modificaram a morfologia do sistema radicular aumentando a área disponível para absorção de nutrientes através da formação de pelos radiculares.

$\mathrm{O}$ pastejo pode alterar a relação entre fonte $\mathrm{e}$ dreno nos órgãos remanescentes da planta (Volenec et al., 1996). Após a remoção da parte aérea as raízes e colmos atuam como órgãos fonte, com o papel de transferir carboidratos e proteínas para as folhas em rebrota (órgãos drenos) até que a área foliar seja reestabelecida. Nesse sentido, Wong \& Stur (1996) ressaltam que as plantas de crescimento rasteiro dependem mais da área foliar residual para recuperar o crescimento, enquanto as de crescimento ereto utilizam para esse propósito, principalmente, as reservas acumuladas na base do colmo e raízes.

Com relação à parte aérea, a fim de aumentar a eficiência de utilização do pasto Peri et al. (2003) propõe que crescimento deve ser interrompido no momento ideal para maximizar a utilização da luz no dossel. Esse autor observou três pontos importantes para explicar a baixa eficiência produtiva do dossel em períodos avançados de rebrota. Com o avançar do crescimento os aumentos em área foliar induz a maiores sombreamentos nas folhas inferiores do estrato. Além disso, ocorre declínio na concentração de nitrogênio com a idade, e também foi constatado, que as folhas recémexpandidas do estrato superior são cronologicamente mais velhas do que as folhas inferiores, hipótese sustentada pela maior condutância estomacal dessas últimas. Essa avaliação confirma os resultados sobre o conceito de índice de área foliar (IAF) crítico, na qual a rebrota deve ser interrompida quando $95 \%$ da luz incidente é interceptada pelo dossel, em pastejo sob lotação intermitente. Trabalho realizado por Pedreira \& Pedreira (2007) constataram que o pastejo mais frequente, utilizando o critério de IAF crítico, proporcionou taxa fotossintética superior nas folhas individuais, e refletiu em maior eficiência de fotossíntese do dossel. O prépastejo estabelecido aos $95 \%$ de interceptação luminosa otimizou o uso da luz pelo dossel por proporcionar uma arquitetura que minimizou a competição por luz, evidenciado pelos menores coeficiente de extinção luminosa (k), além de manter na área folhas mais jovens que utilizam a luz com maior competência. Em lotação intermitente, Braga et al. (2009) avaliaram o efeito da intensidade de pastejo na fotossíntese foliar líquida de Panicum maximum cv. Tanzânia. A taxa de acúmulo de forragem e a fotossíntese foliar líquida não foi influenciada pelos tratamentos, contudo, a capacidade fotossintética do dossel pode ter sido prejudicada nas maiores alturas de resíduo pela presença de maior proporção de colmo e material morto. Esses componentes apresentam baixa capacidade 
fotossintética, que elevam as perdas respiratórias, reduzem a assimilação de carbono e, podem reduzir a produção primária. Trabalhos realizados em lotação contínua, por Dong et al. (2004), revelaram que em pastagens consorciadas as maiores intensidades de pastejo diminuíram a taxa fotossintética das folhas e a área foliar causando declínio na produção líquida de forragem. Em outro estudo, Ferlin et al. (2006) conduziram o experimento para avaliar o efeito de diferentes resíduos de pastejo em Panicum maximum cv. Tanzânia sobre as características morfogênicas. Foi observado que nos menores resíduos ocorreram maiores taxas de aparecimento e alongamento foliar.

Nantes et al. (2013) avaliou o desempenho animal e características de $B$. Brizantha cv. Piatã submetidos ao pastejo em lotação contínua em alturas de15, 30 e $45 \mathrm{~cm}$. Os resultados evidenciam que pastos mantidos nas menores alturas $(15$ e $30 \mathrm{~cm})$ tiveram os maiores ganhos de peso por aérea. Altura de $45 \mathrm{~cm}$ apresentou uma estrutura desfavorável ao pastejo, decorrentes de menores percentagens de folhas e densidade volumétrica de matéria seca, essas características aliada a baixa eficiência de utilização da gramínea comprometeram o ganho dos animais. Resultados semelhantes também foram confirmados por Carloto et al. (2011) em pastos de B. Brizantha cv. Xaraés e por Paula et al. (2012) ao trabalharem com B. Brizantha cv. Marandu, sob as mesmas condições de manejo.

Outra característica bastante modificada pelo pastejo são os perfilhos da comunidade vegetal. Estudos sobre o comportamento do perfilho na pastagem possui importância direta na produtividade e sustentabilidade das pastagens, pois a produção de forragem de toda a comunidade vegetal é baseada na contribuição individual de cada perfilho multiplicado pela sua densidade. Vários trabalhos demonstram a influência do manejo e do clima na comunidade de perfilhos. Nesse sentido, Portela et al. (2011) constataram, em pastos de B. decumbens cv. Basilisk, maiores densidades populacionais de perfilhos nas maiores intensidades e frequência de pastejo em decorrência da menor competição de luz na base do dossel. No entanto, esse padrão de resposta foi modificado no inverno. Nessa época, as reduzidas temperaturas e baixos índices pluviométricos somados ao maior estresse ocasionados por maiores intensidades $\mathrm{e}$ frequências diminuíram a população de perfilhos basais e aéreos. Nessa situação, a plasticidade fenotípica pode ser limitada pela falta de carboidratos não estruturais armazenados na base do colmo e escassez de reservas nitrogenadas. De maneira similar Carvalho et al. (2000) observaram que as maiores intensidades de pastejo proporcionaram maiores densidades populacionais de perfilhos em Cynodon ssp., e também, foi verificado alta renovação da população de perfilhos durante o verão, com as maiores taxas de mortalidade e aparecimento.

$\mathrm{Na}$ literatura, alguns trabalhos relatam efeitos positivos da desfolhação na produção vegetal. Alguns autores (Dong et al., 2004; Ferraro \& Oesterheld, 2002) relatam que a taxa de crescimento na rebrota é proporcionalmente superior a quantidade de tecidos removidos em resposta ao crescimento compensatório dos órgãos remanescentes. Essa resposta em acúmulo de biomassa após a desfolhação pode ser atribuída à flexibilidade de alocação de carbono da raiz pra parte aérea e maior penetração de luz no dossel na base do dossel, que estimula a ativação e proliferação de meristemas, diminui a taxa de senescência foliar e aumente a eficiência de uso da água (Ferraro \& Oesterheld, 2002). Esses autores fizeram uma abordagem complementar com base na regressão linear e meta-análise com vários dados da literatura comparando gramíneas desfolhadas e não desfolhadas, e encontram, taxa de crescimento relativo superior nas plantas cortadas.

\section{Sombra}

A disponibilidade de luz é o maior fator ecológico influenciando o crescimento e sobrevivência das plantas (Guenni et al., 2008). A adaptação das espécies à sombra depende de sua capacidade em desenvolver ajustes morfológicos e fisiológicos para aproveitar os baixos níveis de irradiação disponível.

Trabalhos desenvolvidos por Paciullo et al. (2010) avaliaram a partição de biomassa em $B$. decumbens em diferentes distâncias da copa das árvores. Nas regiões mais sombreadas as gramíneas tiveram menor biomassa de raiz na camada superficial do solo. Dias-Filho (2000) avaliou a alocação de biomassa em $B$. Brizantha e B. humidicola, em condição de $70 \%$ de sombra, e constatou redução da biomassa de raízes em detrimento da parte aérea. Resultados similares foram encontrados por Durr \& Rangel (2000), ao trabalhar com Panicum maximum, onde a razão parte aérea/raiz aumentou com a diminuição da 
radiação fotossinteticamente ativa. Na literatura, essa resposta das plantas é consistente, principalmente, nos maiores níveis de sombra. Esse investimento na parte aérea é utilizado como recurso para aumentar a capacidade da forrageira em interceptar maiores quantidades de radiação em ambiente limitado por esse fator.

Outra mudança, evidente sob baixa luminosidade, é a menor densidade populacional de perfilhos basais. Essa menor população de perfilhos ocorre devido à queda na qualidade $\mathrm{e}$ quantidade de luz que chega à base dos perfilhos, nessas condições a planta prioriza o crescimento dos perfilhos existente como alternativa de reduzir a competição por luz, recurso esse que já se encontra limitado (Dias-Filho, 2002a). Diversos autores encontraram resposta similar para as gramíneas do gênero Brachiaria em experimentos em vaso com o uso de sombrite (Dias-Filho 2000; Baruch \& Guenni 2007; Guenni et al., 2008; Gobbi et al., 2009; Martuscello et al., 2009; Paciullo et al., 2011;) e em trabalhos realizados no campo (Paciullo et al., 2007; Paciullo et al., 2008).

Como resposta anatômica as folhas em ambiente com sombra aumentam a superfície específica da folha. Essa característica implica em diminuir o número de células do mesófilo por unidade de área tornando a folha mais larga e fina, com o objetivo de maximizar a eficiência de captação de luz e melhorar a distribuição da radiação no perfil do dossel. Alguns autores (Durr \& Rangel, 2000; Dias-Filho, 2000; Guenni et al., 2008; Baruch \& Guenni, 2007) relatam esse padrão de resposta na literatura.

Além das adaptações morfológicas, as plantas exibem alterações fisiológicas importantes para compensar a baixa luminosidade. Nesse ambiente, as folhas aumentam o teor de clorofila, de modo, a potencializar a absorção da radiação fotossinteticamente ativa no ambiente escasso por esse recurso (Cruz, 1997; Baruch \& Guenni, 2007). De maneira geral, em condição de baixa disponibilidade de luz as plantas com maior capacidade de aclimatação competem por esse recurso priorizando a formação da parte aérea para aumentar a captação de luz. Porém, é válido destacar que essas modificações podem deixar a planta mais sensível a outros tipos de estresse como o pastejo, assim devem ser levadas em consideração para estabelecer manejo adequado, a fim de não comprometer a perenidade $\mathrm{e}$ produtividade da gramínea (Wong \& Stur, 1996; Baruch \& Guenni, 2007; Guenni et al., 2008).

\section{Deficiência de nutrientes}

A falta ou insuficiência de nutrientes debilita e atrasa o desenvolvimento das plantas, por isso o efeito geral mais importante das deficiências minerais é a redução do ritmo de crescimento das plantas. A deficiência de nutrientes pode ser estabelecida pela falta de reposição de nutrientes, ou por outros fatores, como foi abordado nos tópicos anteriores (seca, alagamento e compactação) que atuam limitando a absorção de nutrientes pelas gramíneas.

Em condições de alta disponibilidade de nutrientes, Pereira et al. (2010) observaram que a aplicação nitrogênio acelerou as taxas de aparecimento foliar estimulando o aumento na população de perfilho em cada gema recémformada. Esse estímulo no crescimento individual e populacional de perfilhos jovens contribui para elevar a densidade de forragem no dossel. Também foi verificado por Lavres Jr. et al. (2004) respostas morfológicas promovidas pelo aumento de nitrogênio na solução nutritiva, com incrementos positivos no número de perfilhos, taxa de aparecimento foliar e número de folhas expandidas, características essas, que em conjunto contribuíram para aumentar a área foliar. Em trabalhos realizados com a omissão do nitrogênio foram observados diminuição do número de folhas, perfilhos e biomassa de raiz (Avalhaes et al., 2009). Comportamento similar da forrageira foram verificados por Monteiro et al. (1995), após a retirada de nitrogênio e fósforo da solução nutritiva, mas o mesmo não ocorreu com o potássio.

A deficiência de nitrogênio pode alterar substancialmente a partição de biomassa na planta e a morfologia das raízes. Alguns autores (Hermans et al., 2006) descrevem que a deficiência de nitrogênio acumula açúcares nas folhas, por razões ainda desconhecidas, o que aumenta o suprimento de sacarose e hexoses para as raízes. Esses açúcares atuam no sistema radicular promovendo a diferenciação, maturação e expansão celular, em consequência desse processo, as plantas aceleram o crescimento das raízes na busca pelos nutrientes limitantes. Estudo realizado por Giacomini et al. (2005) verificaram maior superfície específica e comprimento de raízes nas menores adubações, 
como adaptação das forrageiras em explorar maior volume de solo na busca por recursos.

De maneira resumida, pode-se verificar no Quadro 1 os tipos de estresse ocasionado pelos fatores bióticos e abióticos, assim como as respostas das plantas a essas condições adversas. As modificações morfológicas e ou fisiológicas apresentadas pelas espécies forrageiras são estratégias das comunidades vegetais mais adaptadas ao ecossistema ao qual estão inseridas.

Quadro 1. Estresse ocasionado por fatores bióticos e abióticos e resposta adaptativa da planta

\begin{tabular}{|c|c|c|}
\hline Fatores & Estresse à planta & Resposta da planta \\
\hline Compactação & prejudica o crescimento radicular ${ }^{1}$ & $\begin{array}{l}\text { emissão de raízes laterais }{ }^{1} \\
\text { engrossamento das raízes }^{2}\end{array}$ \\
\hline Alagamento & $\begin{array}{l}\text { baixa disponibilidade de } \mathrm{ATP}^{3} \\
\text { espécies reativas de oxigênio } \\
\text { níveis tóxicos de elementos } \\
\text { menor condutância estomática }\end{array}$ & $\begin{array}{l}\text { formação de raízes adventícias }{ }^{4,5} \\
\text { diminuição da biomassa de raízes }\end{array}$ \\
\hline Seca & $\begin{array}{l}\text { espécies reativas de oxigênio }{ }^{7} \\
\text { menor assimilação de carbono }\end{array}$ & $\begin{array}{l}\text { diminuição da abertura do estômato } \\
\text { diminuição do diâmetro do estômato } \\
{ }^{8} \\
\text { ajustamento osmótico da célula }{ }^{7,8,9} \\
\text { aprofundamento das raízes }{ }^{10}\end{array}$ \\
\hline Pastejo & diminuição do aparato fotossintético & $\begin{array}{l}\text { mudança na relação fonte e dreno } \\
\text { alteração na população de perfilhos } \\
12,13\end{array}$ \\
\hline Sombra & diminuição da radiação solar & $\begin{array}{l}\text { aumento na razão parte aérea/raiz }{ }^{14,15,16} \\
\text { diminuição do perfilhamento } \\
\text { aumento da superfície } \\
\text { específica da folha }{ }^{15,16,17,21} \\
\text { aumento no teor de clorofila } \\
\end{array}$ \\
\hline Deficiência de Nutrientes & falta de elementos essenciais & $\begin{array}{l}\text { acelera o crescimento das raízes }{ }^{23} \\
\text { aumenta a superfície } \\
\text { e comprimento das raízes }{ }^{24}\end{array}$ \\
\hline
\end{tabular}

Fonte: ${ }^{1}$ Bengough et al. (2006); ${ }^{2}$ Reinert et al. (2008); ${ }^{3}$ Colmer \& Voesenec (2009); ${ }^{4}$ Baruch (1994); ${ }^{5}$ Mattos et al. (2005); ${ }^{6}$ Dias-Filho (2002); ${ }^{7}$ Mahajan \& Tuteja (2005); ${ }^{8}$ Melo et al. (2007); ${ }^{9}$ Singh et al. (2000); ${ }^{10}$ Guenni et al. (2002); ${ }^{11}$ Volenec et al. (1996); ${ }^{12}$ Portela et al. (2011); ${ }^{13}$ Carvalho et al. (2000); ${ }^{14}$ Paciullo et al. (2010); ${ }^{15}$ Dias-Filho (2000); ${ }^{16}$ Durr \& Rangel (2000); ${ }^{17} \mathrm{Guenni}$ et al. (2008); ${ }^{18} \mathrm{Gobbi}$ et al. (2009); ${ }^{19}$ Martuscello et al. (2009); ${ }^{20}$ Paciullo et al. (2011); ${ }^{21}$ Baruch \& Guenni (2007); ${ }^{22} \mathrm{Cruz}$ (1997); ${ }^{23} \mathrm{Hermans}$ et al. (2006); ${ }^{24} \mathrm{Giacomini}$ et al. (2005).

\section{Considerações Finais}

Nos sistemas produtivos as plantas forrageiras, inevitavelmente, estarão submetidas a algum tipo de estresse, por isso é importante compreender as relações de causas e efeitos que influenciam o crescimento e desenvolvimento das plantas nas diversas situações em que um ou mais fatores podem alterar as respostas produtivas.

As adaptações da planta aos eventos desfavoráveis podem implicar em alterações nas características morfológicas e fisiológicas para garantir a sua sobrevivência, mas que não necessariamente implicam em manutenção da produção dos órgãos de interesse. Contudo, tais modificações devem ser conhecidas para respeitar os limites de utilização e garantir a eficiência de produção das forrageiras.

\section{Referências Bibliográficas}

Arvidsson, J. (1999). Nutrient uptake and growth of barley as affected by soil compaction. Plant and Soil, 208, 9-19.

Avalhaes, C. C., Prado, R. D. M., Rozane, D. E., Romualdo, M. \& Correia, M. A. R. (2009). 
Macronutrients omission and the growth and nutritional status of elephant grass (cv. Mott) growing in nutrient solution. Scientia Agraria, $10,215-222$.

Baruch, Z. \& Guenni, O. (2007). Irradiance and defoliation effects in three species of the forage grass Brachiaria. Tropical Grasslands, 41, p. 269.

Baruch, Z. (1994). Responses to drought and flooding in tropical forage grasses. Plant and Soil, 164, 87-96.

Bengough-Glyn. A., Bransby, M. F., Hans, J., McKenna, S. J., Roberts, T. J. \& Valentine, T. A. (2006). Root responses to soil physical conditions; growth dynamics from field to cell. Journal of Experimental Botany, 57, 437447.

Braga, G. J., Mello, A. D., Pedreira, C. G. S., \& Medeiros, H. D. (2009). Fotossíntese e taxa diária de produção de forragem em pastagens de capim-tanzânia sob lotação intermitente. Pesquisa Agropecuária Brasileira, 44, 84-91.

Cabral, C. E., Bonfim-Silva, E. M., Bonelli, E. A., Da Silva, T. J., Cabral, C. H., \& Scaramuzza, W. L. (2012). Soil compaction and primary macronutrients in Brachiaria brizantha cv. Piatã e Panicum maximum cv. Mombaça. Revista Brasileira de Engenharia Agrícola e Ambiental, 16, 362-367.

Caetano, L. P. D. S. \& Dias-Filho, M. B. (2008). Responses of six Brachiaria spp. accessions to root zone flooding. Revista Brasileira de Zootecnia, 37, 795-801.

Carloto, M. N., Euclides, V. P. B., Montagner, D. B., Lempp, B., Difante, G. D. S., \& Paula, C. D. (2011). Desempenho animal e características de pasto de capim-xaraés sob diferentes intensidades de pastejo, durante o período das águas. Pesquisa Agropecuária Brasileira, 46, 97-104.

Carvalho, C. D., Da Silva, S. C., Sbrissia, A. F., Pinto, L. D. M., Carnevalli, R. A., Fagundes, J. L., \& Pedreira, C. G. S. (2000). Demografia do perfilhamento e taxas de acúmulo de matéria seca em capim tifton 85 sob pastejo. Scientia Agricola, 57, 591-600.

Chaves, M. M., Maroco, J. P. \& Pereira, J. S. (2003). Understanding plant responses to drought-from genes to the whole plant. Functional plant biology, 30, 239-264.
Colmer, T. D. \& Voesenek, L. A. C. J. (2009). Flooding tolerance: suites of plant traits in variable environments. Functional Plant Biology, 36, 665-681.

Cruz, P. (1997). Effect of shade on the growth and mineral nutrition of a $\mathrm{C} 4$ perennial grass under field conditions. Plant and Soil, 188, 227-237.

Dias-Filho, M. B. \& Carvalho, C. J. R. D. (2000). Physiological and morphological responces of Brachiaria spp. to flooding. Pesquisa Agropecuária Brasileira, 35, 1959-1966.

Dias-Filho, M. B. (2000). Growth and biomass allocation of the $\mathrm{C} 4$ grasses Brachiaria brizantha and B. humidicola under shade. Pesquisa Agropecuária Brasileira, 35, 23352341.

Dias-Filho, M. B. (2002a). Photosynthetic light response of the $\mathrm{C} 4$ grasses Brachiaria brizantha and $B$. humidicola under shade. Scientia Agricola, 59, 65-68.

Dias-Filho, M. B. (2002b). Tolerance to flooding in five Brachiaria brizantha accessions. Pesquisa Agropecuária Brasileira, 37, 439447.

Dong, S. K., Kang, M. Y., Hu, Z. Z., Long, R., \& $\mathrm{Pu}, \mathrm{X}$. P. (2004). Performance of cultivated perennial grass mixtures under different grazing intensities in the alpine region of the Qinghai Tibetan Plateau. Grass and Forage Science, 59, 298-306.

Durr, P. A. \& Rangel, J. (2000). The response of Panicum maximum to a simulated subcanopy. Tropical Grasslands, 34, 110-117.

Farooq, M., Wahid, A., Kobayashi, N., Fujita, D., \& Basra, S. M. A. (2009). Plant drought stress: effects, mechanisms and management. Sustainable Agriculture. Springer Netherlands, p. 153-188.

Ferlin, M. B., Euclides, V. P. B., Lempp, B., Gonçalves, M. C., \& Cubas, A. C. (2006). Morfogênese e dinâmica do perfilhamento de Panicum maximum jacq. cv. Tanzânia sob pastejo. Ciência e Agrotecnologia, 30, 344352.

Ferraro, D. O. \& Oesterheld, M. (2002). Effect of defoliation on grass growth. A quantitative review. Oikos, 98, 125-133.

Giacomini, A. A., Mattos, W. T. D., Mattos, H. B. D., Werner, J. C., Cunha, E. A. D., \& 
Carvalho, D. D. D. (2005). Crescimento de raízes de capins Aruana e Tanzânia submetidos a duas doses de nitrogênio. Reunião Anual da Sociedade Brasileira de Zootecnia, 42.

Gobbi, K.F., Garcia, R., Neto, A.F.G., Gomes, O., Ventrella, P.M.C. \& Rocha, G.C. (2009). Características morfológicas, estruturais e produtividade do capim braquiária e do amendoim forrageiro submetidos ao sombreamento. Revista Brasileira de Zootecnia, 38, 1645-1654.

Gomide, C.A.M., Gomide, J.A. \& Martinez, C.A. (2002). Fotossíntese, reservas orgânicas e rebrota do capim-mobaça (Panicum maximum, Jacq.) sob diferentes intensidades de desfolha do perfilho principal. Revista Brasileira de Zootecnia, 31, 2165-2175.

Guenni, O., Baruch, Z. \& Marín, D. (2004). Responses to drought of five Brachiaria species. II. Water relations and leaf gas exchange. Plant and Soil, 258, 249-260.

Guenni, O., Marín, D. \& Baruch, Z. (2002). Responses to drought of five Brachiaria species. I. Biomass production, leaf growth, root distribution, water use and forage quality. Plant and Soil, 243, 229-241.

Guenni, O., Saiter, S. \& Figueroa, R. (2008). Growth responses of three Brachiaria species to light intensity and nitrogen supply. Tropical Grasslands, 42, 75-87.

Haddad, C. M. Platzeck, C. O., Tamassia, L. F. M. \& Castro, F. G. F. (2000). Estabelecimento do capim setária cv. Kazungula em condições de inundação. Scientia Agricola, 57, 205-212.

Harrison, D. F., Cameron, K. C. \& Mclaren, R. G. (1994). Effects of subsoil loosening on soil physical properties, plant root growth, and pasture yield. New Zealand Journal of Agricultural Research, 37, 559-567.

Hermans, C., Hammond, J. P., White, P. J., \& Verbruggen, N. (2006). How do plants respond to nutrient shortage by biomass allocation?. Trends in plant science, 11, 610617.

IPCC. (2007). - Intergovernmental Panel On Climate Change. Climate change. Fourth Assessment Report on climate change impacts, adaptation and vulnerability of the Intergovernmental Panel on Climate Change. Cambridge, Cambridge University. 939p.
Lavres Jr, J., Ferragine, M. D. C., Gerdes, L., Raposo, R. W. C., Costa, M. N. X. D., \& Monteiro, F. A. (2004). Yield components and morphogenesis of Aruana grass in response to nitrogen supply. Scientia Agricola, 61, 632639.

Lemaire, G. (2001). Ecophysiology of grasslands: dynamic aspects of forage plant populations in grazed swards. In: International Grassland Congress. São Paulo: SBZ, 2001. 29-37.

Mahajan, S. \& Tuteja, N. (2005). Cold, salinity and drought stresses: an overview. Archives of Biochemistry and Biophysics, 444, 139-158.

Martuscello, J.A., Jank, L., Neto, M.M.G., Laura, V.A. \& Cunha, D.N.F.V. (2009). Produção de gramíneas do gênero Brachiaria sob níveis de sombreamento. Revista Brasileira Zootecnia, 38, 1183-1190.

Mattos, J. L. S., Gomide, J. A., M. Y. H. \& Carlos, A. (2005a). Crescimento de espécies do gênero Brachiaria sob alagamento em casa de vegetação. Revista Brasileira de Zootecnia, 34, 675-773.

Mattos, J. L. S., Gomide, J. A., M. Y. H. \& Carlos, A. (2005b). Crescimento de espécies do gênero Brachiaria, sob déficit hídrico, em casa de vegetação. Revista Brasileira de Zootecnia, 34, 746-754.

Melo, H. D., Castro, E. D., Soares, A. M., Melo, L. D., \& Alves, J. D. (2007). Alterações anatômicas e fisiológicas em Setaria anceps Stapf ex Massey e Paspalum paniculatum L. sob condições de déficit hídrico. Hoehnea, 34, 145-153.

Monteiro, F. A., Ramos, A. K. B., Carvalho, D. D., Abreu, J. D., Daiub, J. A. S., Silva, J. D., \& Natale, W. (1995). Cultivo de Brachiaria brizantha Stapf. cv. Marandu em solução nutritiva com omissões de macronutrientes. Scientia Agricola, 52, 135-141.

Nantes, N. N., Euclides, V. P. B., Montagner, D. B., Lempp, B., Barbosa, R. A., \& Gois, P. O. (2013). Desempenho Animal e Características de Pastos de Capim-Piatã Submetidos a Diferentes Intensidades de Pastejo. Pesquisa Agropecuária Brasileira, 48, 114-121.

Paciullo, D. S. C. (2008). Crescimento de capimbraquiária influenciado pelo grau de sombreamento e pela estação do ano. 
Pesquisa Agropecuária Brasileira, 43, 917923.

Paciullo, D. S. C. (2011). The growth dynamics in Brachiaria species according to nitrogen dose and shade. Revista Brasileira de Zootecnia, 40, 270-276.

Paciullo, D. S. C., Castro, C. R. T. D., Gomide, C. A. D. M., Fernandes, P. B., Rocha, W. S. D. D., Müller, M. D., \& Rossiello, R. O. P. (2010). Soil bulk density and biomass partitioning of Brachiaria decumbens in a silvopastoral system. Scientia Agricola, 67, 598-603.

Paciullo, D.S.C., Carvalho, C.A.B., Aroeira, L.J.M., Morenz, M.J.F., Lopes F.C.F. \& Rossiello, R.O.P. (2007). Morfofisiologia e valor nutritivo do capim-braquiária sob sombreamento natural e a sol pleno. Pesquisa Agropecuária Brasil, 42, 573-579.

Paula, C. C., Euclides, V. P., Montagner, D. B., Lempp, B., Difante, G. S., \& Carloto, M. N. (2012). Estrutura do dossel, consumo e desempenho animal em pastos de capimmarandu sob lotação contínua. Arquivo Brasileiro de Medicina Veterinária $e$ Zootecnia, 64, 169-176.

Pedreira, B. C. \& Pedreiras, C. G. S (2007). Fotossíntese foliar do capim-xaraés [Brachiaria brizantha (A. Rich.) Stapf. cv. Xaraés] e modelagem da assimilação potencial de dosséis sob estratégias de pastejo rotativo. Revista Brasileira de Zootecnia, 36, 773-779.

Pereira, L. E. T., Paiva, A. J., Silva, S. C. D., Caminha, F. O., Guarda, V. D. Á., \& Pereira, P. D. M. (2010). Sward structure of marandu palisadegrass subjected to continuous stocking and nitrogen-induced rhythms of growth. Scientia Agricola, 67, 531-539.

Peri, P. L., Moot, D. J., Mcneil, D. L., \& Lucas, R. J. (2003). Modelling net photosynthetic rate of field grown cocksfoot leaves to account for regrowth duration. New Zealand Journal of Agricultural Research, 46, 105115.

Portela, J. N., Pedreira, Carlos, G. S. \& Braga, G. J. (2011). Demografia e densidade de perfilhos de capim-braquiária sob pastejo em lotação intermitente. Pesquisa Agropecuária Brasileira, 46, 315-322.
Reichert, J. M., Reinert, D. J. \& Braida, J. A. (2003). Qualidade dos solos e sustentabilidade de sistemas agrícolas. Ciência Ambiental, 27, 29-48.

Reichert, J. M., Suzukia, L. E. A., Reinert, D. J., Horn, R. \& Håkansson (2009). Reference bulk density and critical degree-of-compactness for no-till crop production in subtropical highly weathered soils. Soil and Tillage Research, 102, 242-254.

Reinert, D. J., Albuquerque, J. A., Reichert, J.M., Aita, C. \& Andrada, M. M. C. (2008). Limites críticos de densidade do solo para o crescimento de raízes de plantas de cobertura em Argissolo Vermelho. Revista Brasileira de Ciência do Solo, 32, 1805-1816.

Richart, A., Tavares Filho, J., Brito, O. R., Llanillo, R. F. \& Ferreira, R. (2005). Compactação do solo: causas e efeitos. Semina: Ciências Agrárias, 26, 321-344.

Rosenthal, J. P. \& Kotanen, P. M. (1994). Terrestrial plant tolerance to herbivory. Trends in Ecology \& Evolution, 9, 145-148.

Santos, P. M., Santos, P. M., Cruz, P. G., Araujo L. C., Pezzopane, R. M., Valle, C. B. \& Pezzopane, C. B. (2013). Response mechanisms of Brachiaria brizantha cultivars to water deficit stress. Revista Brasileira de Zootecnia, 42, 767-773.

Silva, S. C. D. \& Nascimento Júnior, D. D. (2007). Avanços na pesquisa com plantas forrageiras tropicais em pastagens: características morfofisiológicas e manejo do pastejo. Revista Brasileira de Zootecnia, 36, 122-138.

Silva, S. C., Nascimento Júnior, D. \& Euclides, V. B. P. (2008). Pastagens: conceitos básicos, produção e manejo. Suprema.

Singh, D. K., Sale, P. W. G., Pallaghy, C. K. \& Singh, V. (2000). Role of proline and leaf expansion rate in the recovery of stressed white clover leaves with increased phosphorus concentration. New Phytologist, 146, 261-269.

Stirzaker, R. J., Passioura, J. B. \& Wilms, Y. (1996). Soil structure and plant growth: impact of bulk density and biopores. Plant and Soil, 185, 151-162.

Thornton, B. \& Millard, P. (1996). Effects of severity of defoliation on root functioning in 
grasses. Journal of Range Management, p. 443-447.

Torres, E. \& Saraiva, O. F. (1999). Camadas de impedimento mecânico do solo em sistemas agrícolas com a soja. Embrapa Soja,

Vizzotto, V. R., Enio, M. \& Tommi S. (2000). Efeito do pisoteio bovino em algumas propriedades físicas do solo de várzea. Ciência Rural, 30, 965-969.

Voesenek, L. A. \& Pierik, R. (2008). Plant stress profiles. Science, 320, 880-881.

Volenec, J. J., Ourry, A. \& Joern, B. C. (1996). A role for nitrogen reserves in forage regrowth and stress tolerance. Physiologia Plantarum, 97, 185-193.

Wong, C. C. \& Stur, W. W. 1996. Persistence of tropical forage grasses in shaded environments. The Journal of Agricultural Science, 126, 151-159.

\section{Article History}

Received 16 June 2016

Accepted 05 July 2016

Available on line 26 July 2016

License information: This is an open-access article distributed under the terms of the Creative Commons Attribution License, which permits unrestricted use, distribution, and reproduction in any medium, provided the original work is properly cited. 